\title{
Implementation of a V/f Controlled Variable Speed Induction Motor Drive
}

\section{Zeynep Bala Duranay, Hanifi Guldemir, Servet Tuncer}

\author{
Firat University, Technology Faculty, \\ Electrical-Electronics Engineering Elazig/Turkey \\ Email: zbduranay@firat.edu.tr, hguldemir@firat.edu.tr, stuncer@firat.edu.tr
}

Received March 24, 2020; Revised April 17, 2020; Accepted May 9, 2020

\begin{abstract}
DSP implementation of speed control of three phase induction motor drive is presented in this paper. A closed loop speed control has been achieved using constant $\mathrm{V} / \mathrm{f}$ technique which is a simple scalar control method used to control the magnitude of the control quantities. In this study, a fourth order polynomial drived from $\mathrm{V} / \mathrm{f}$ curve is constructed instead of using look up table which takes much time for determination of voltage from frequency value. A PI controller is used in speed control. dSPACE DS-1103 controller board is used for the implementation with Matlab/Simulink, which has a simple real time interface. Steady-state speed characteristics and transient responses with various reference speed commands are presented by experimental system. The simulation and experimental results provide a smooth speed response and good performance under various dynamic operations. Real time speed control has been implemented and some results are presented.
\end{abstract}

Keywords: frequency control, induction motors, motor drives, speed control, variable speed drive.

\section{INTRODUCTION}

Many industrial applications need adjustable speed drives. Conveyors, machine tools, blowers are some of the application examples which require speed control. Because induction motors are fixed speed motors, DC motors were used for the variable speed drives because of their speed and torque characteristics. However, the mechanical contacts with commutator and brushes which produce problems with time are some of the drawbacks of DC motors. Due to its low cost, simple structure, low maintenance, robustness and reliability, induction motors are widely used in many applications in residential, industrial and commercial areas [1], [2]. However, the speed control of induction motors is more difficult due to their complex structure [3], [4]. 


\section{RELATED WORKS}

The achievements in power electronics have improved the adjustable speed induction motor drives to obtain smooth and continuous speed variation. The speed of these motors can be controlled using either scalar or vector control techniques. In scalar control techniques, the motor speed is controlled by changing the amplitude or frequency of the supply voltage connected to the induction motor [5], [6]. Scalar control is a simple method which can be easily implemented for speed control [7], [8]. This technique provides satisfactory response in the steady state. The main drawback is the poor performance during transients. The motor performance becomes poor at low speed region [9].

The scalar control cannot provide good accuracy in speed and torque control due to the coupling between stator current components which produce torque and flux. Because of this coupling, the stator flux and torque cannot be controlled directly. Vector control techniques are used with the applications where a high performance with better accuracy is needed [10][15]. The speed of the induction motor can be controlled by using solid-state variable-frequency induction motor drive. PWM techniques are used to control the output voltage and frequency. It is aimed in this study to implement a real time constant $\mathrm{V} / \mathrm{f}$ controlled variable speed squirrel cage induction motor drive.

\section{ORIGINALITY}

The torque produced by induction motors is created by interaction of stator and rotor magnetic fields. If frequency is reduced while the voltage kept costant with a certain value, then magnetic saturation occurs due to the large magnetic flux causing failure of the motor. Because of this, the voltage and frequency should be changed proportionally resulting constant voltage and frequency ratio. This is known as constant $\mathrm{V} / \mathrm{f}$ control of induction motors. In this control method the speed of the induction motor is controlled with the stator voltage and frequency by maintaining the airgap flux at the desired steady state value.

For constant V/f control, the values of the voltage and frequency need to be stored. Normally, look up tables are used for storing voltage and frequency values. There should be a voltage value for every frequency value. If small changes are needed either the look up table to be too long or interpolation between the values should be used. This need large storage and too much time fort he computations.

In this study a polynomial is constructed from the $V / f$ curve. A fourth order polynomial, as explained in Section 6, is constructed to represent the $\mathrm{V} / \mathrm{f}$ curve. Thus, the voltage value corresponding to any frequency value is easily obtained. With this constant $\mathrm{V} / \mathrm{f}$ ratio, the maximum torque of the motor becomes constant for different speed values. 


\section{SYSTEM DESIGN}

\section{STEADY-STATE MODEL OF INDUCTION MOTOR}

The approximate equivalent circuit of an induction motor with respect to the stator, shown in Figure 1, can be used without very much loss of accuracy.

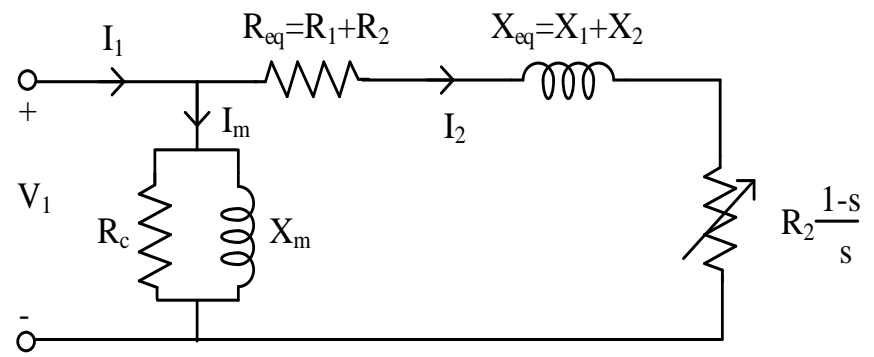

Figure 1. Approximate equivalent circuit of an induction motor

where $\mathrm{V}_{1}, \mathrm{R}_{1}$ and $\mathrm{X}_{1}$ represent voltage, resistance and the leakage reactance of stator winding. $X_{m}$ is the magnetizing reactance and $R_{c}$ represents the core loss.

From per phase equivalent circuit, the rotor current referred to stator $\mathrm{I}_{2}$ can be written as:

$$
I_{2}=\frac{V_{1}}{R_{e q}+R_{2}(1-s) / s+j\left(X_{e q}+X_{2}\right)}
$$

In this expression $\mathrm{R}_{2}$ and $\mathrm{X}_{2}$ represent resistance and leakage reactance of the rotor and s represents the slip.

The induced electromagnetic torque is obtained by [16], [17]:

$$
T=\frac{P}{\omega}=\frac{3 V_{1}^{2} R_{2} / s}{\left(R_{e q}+R_{2} / s\right)^{2}+\left(X_{e q}+X_{2}\right)^{2}}
$$

where $\mathrm{P}$ represents the poles and $\omega$ represents the angular speed of the motor. The curve representing the change of torque with the slip according to Eq. (2) is shown in Figure 2. 


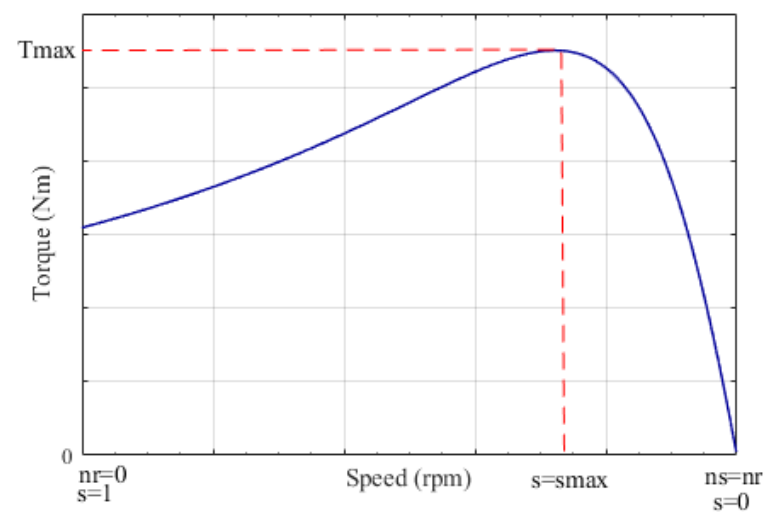

Figure 2. Speed-torque characteristics

\section{SPEED CONTROL OF INDUCTION MOTOR}

The induction motor is a constant speed motor when fed by a constant frequency and constant voltage supply. The speed of this motor can be changed by changing the number of poles, changing the supply frequency or by changing the supply voltage.

The steady state speed of an induction motor is obtained by the expression;

$$
n_{s}=\frac{60 f}{P}
$$

where $\mathrm{n}_{\mathrm{s}}$ represents the synchronous speed, $f$ represents the mains frequency.

The number of poles are determined by stator coil connections. This requires stator winding that can be so arranged to produce different number of pole pairs. Motor needs a special mechanism to change coil connections to change speed. By changing coil connections, the speed change becomes a stepped form and limited with two different speeds with a ratio of 2 to 1 .

The operating slip of an squirrel cage asynchronous motor slightly varies by the source voltage [18]. Therefore, the asynchronous motor speed also changes in a limited region with changing the supply voltage. Figure 2 shows the variation of torque with the slip which is the speed-torque characteristics of an induction motor. Under constant load torque, the speed change can only be made between $0\left(\mathrm{n}_{\mathrm{r}}=\mathrm{n}_{\mathrm{s}}\right)$ slip and maximum slip ( $\left.\mathrm{s}=\mathrm{s}_{\max }\right)$ region which is the stable operation region.

The torque produced by the asynchronous motor increases with the square of supply voltage. Figure 3 shows the torque-speed characteristics of an asynchronous motor with different supply voltages. 


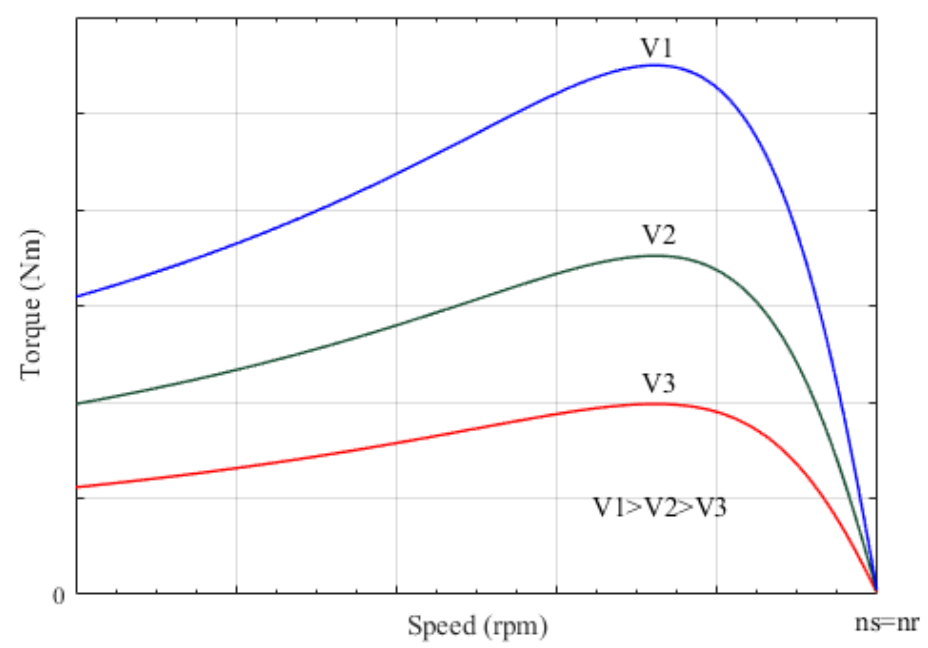

Figure 3. Speed-torque curves for different voltage values

As seen in Figure 3, the decrease in the voltage causes a big drop in torque. However, the voltage change does not affect the speed and the maximum slip where pull-out torque is generated. The speed range for stable operation doesn't change. The starting torque also decrease with decreasing voltage. The motor may not start even with sufficient voltage level at running torque. This method of speed control is used with the load which requires low starting torque and the torque increase with the speed such as fan type load where the torque directly changes with the square of the speed (T $\alpha \omega^{2}$ ). Because the load torque is zero at zero speed, the motor can start with low voltages.

The speed of induction motor changes changing line frequency. As the developed torque is dependent on the frequency change in frequency causes the change in developed torque. To maintain a constant maximum torque, the voltage should be changed with the frequency.

It is seen in Eq. (3) that there is a direct proportionality between motor speed and the frequency,

$$
n_{s} \alpha \frac{f}{P}
$$

The pole pair is determined at construction stage and its constant. The frequency is the only parameter which determines the speed.

The motor speed can be changed below or above the base speed by changing the frequency above or below the mains frequency. This can be made by using power electronic devices called inverters producing ac voltage with desired frequency from a dc power sources. The amplitude and frequency of the output voltage of an inverter may be variable or fix depending on the method used for switching.

The rotor speed is determined by the synchronous frequency and the load of the motor. The speed can be varied between synchronous speed and 
the maximum speed where pull out torque is generated. The decrease in frequency decreases the speed, but causes increase in pull out torque and the rotor current. Increase in pull out torque with decrease in frequency, as shown in Figure 4, cannot cause motor to benefit from this capacity as it has no need to use this capacity. Motor draws unnecessary high currents near zero speed. Hence, although the speed can be controlled in a wide range by frequency change, it is not useful due to high current drawn from the mains which cause saturation and loss at low or near zero speed.

The induced emf in induction motor is given by,

$$
V=4.44 N \phi_{m} f
$$

where $\mathrm{N}$ represents the number of turns in the winding per phase, $\phi \mathrm{m}$ represents maximum value of the airgap flux.

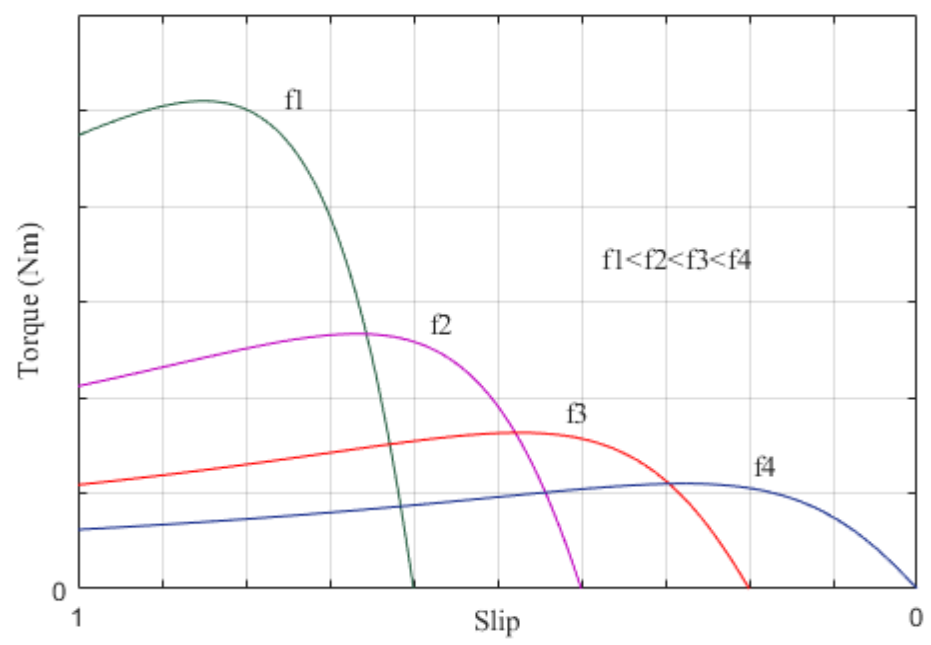

Figure 4. Speed-torque curves for different frequency

When the frequency is reduced to reduce the speed while voltage is constant, the flux must be increased in order to keep the induced emf constant. Increase in flux causes saturation. In order to avoid saturation, the flux need to be kept constant. This requires the voltage has to be reduced with the frequency. This $\mathrm{V} / \mathrm{f}$ ratio needs to be kept same for all frequencies to obtain a flux which produces maximum torque.

When constant voltage/frequency ratio is maintained, a wide range speed change can be reached except near zero speed. This provides pull out torque and therefore the motor current remains to be constant. A high voltage value greater than the specified $\mathrm{V} / \mathrm{f}$ ratio may be applied to the motor to meet the voltage drop across the motor winding as it has a big effect near zero speed. Figure 5 shows the voltage/frequency change curve based on the $\mathrm{V} / \mathrm{f}$ control technique. 


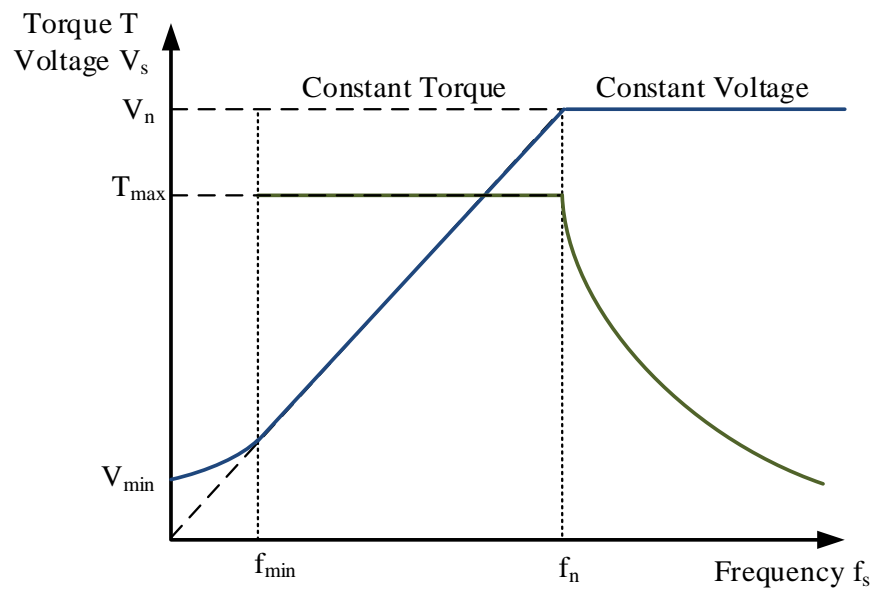

Figure 5. Voltage/frequency characteristics

Figure 6 shows the torque-speed curves of the motor for various voltage and frequency values by maintaining constant $\mathrm{V} / \mathrm{f}$ ratio. The voltage/frequency ratio is taken linearly except for the low speed range.

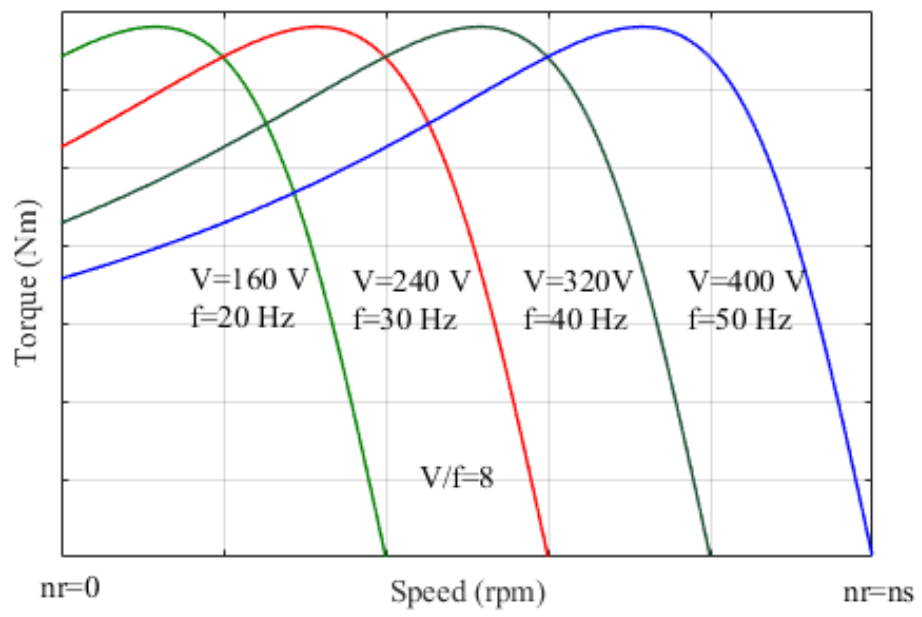

Figure 6. Speed/torque curves with constant $\mathrm{V} / \mathrm{f}$ ratio

In order to obtain a speed higher than the synchronous speed, the frequency and the voltage should be greater than the nominal values to keep constant V/f ratio. Since the voltage higher than the nominal voltage is a problem for the windings, it held constant at the frequencies over the nominal frequency.

\section{MODEL OF THE DRIVE SYSTEM}

Due to the low cost and simplicity, the open loop constant $\mathrm{V} / \mathrm{f}$ control is mostly used speed control technique of induction motor. In open loop control method, the torque cannot be controlled. The change in load torque cause the change in the speed of the motor. This is the main drawback of the open loop control. A more robust technique for controlling the speed of the induction 
motor is the closed loop control technique. In the closed loop control method, the torque is also controlled.

The block diagram of the closed loop speed control of drive system is shown in Figure 7. The error between measured and desired speed is processed in the PI controller. The output of the controller defines the slip speed command $\omega_{\text {sl. }}$. The PWM based three phase inverter frequency was obtained from the motor speed. The measured rotor speed $\omega r$ and the slip speed $\omega_{\text {sl }}$ are added to produce the synchronous speed.

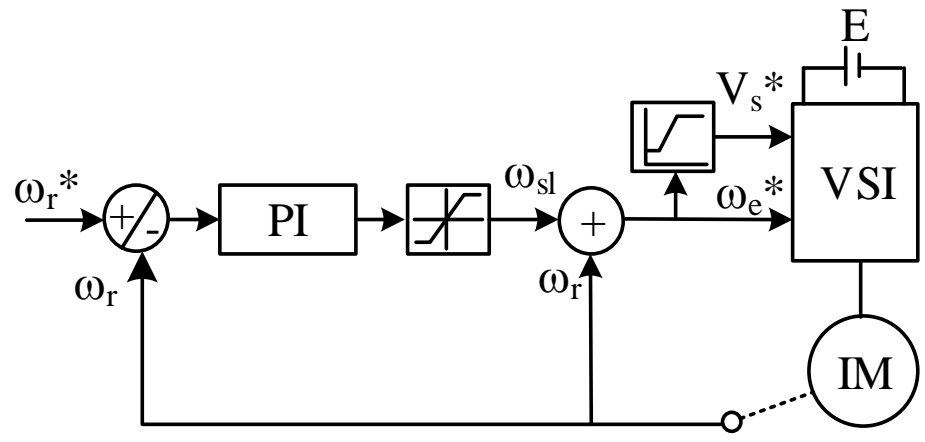

Figure 7. Closed loop speed control system

Frequency $\omega_{\mathrm{e}}$ is used as a reference signal for the $\mathrm{V} / \mathrm{f}$ block of which produces the induction motor terminal voltage $\mathrm{V}_{s}{ }^{*}$. Using information in Figure 5, within the linear region, the reference voltage based on the reference frequency can be written as

$$
V_{s}^{*}=\left(\frac{V_{n}-V_{\min }}{f_{n}-f_{\min }}\right) f_{s}^{*}
$$

$V_{n}$ and $f_{n}$ represent the nominal values, $V_{\min }$ and $f_{\min }$ represent the minimum values of the voltage and frequency respectively.

Normally look up table is used to save numerical values of the voltage and frequency. Look up table might be long for better resolution or interpolation may be needed. For quick response, a polynomial based on $\mathrm{V} / \mathrm{f}$ curve is constructed as shown in Figure 8, instead of using look up table. A fourth degree polynomial given in Eq. (7) is fitted using Matlab curve fitting function. Nominal voltage and frequency values are used fort he construction of this polynomial. This curve is used to obtain voltage values from the frequency representing the speed for all working conditions defined by Eq.(6).

$$
V_{s}^{*}=4.3 \times 10^{-5} f^{4}-0.0091 f^{3}+0.55 f^{2}-4.2 f+75
$$




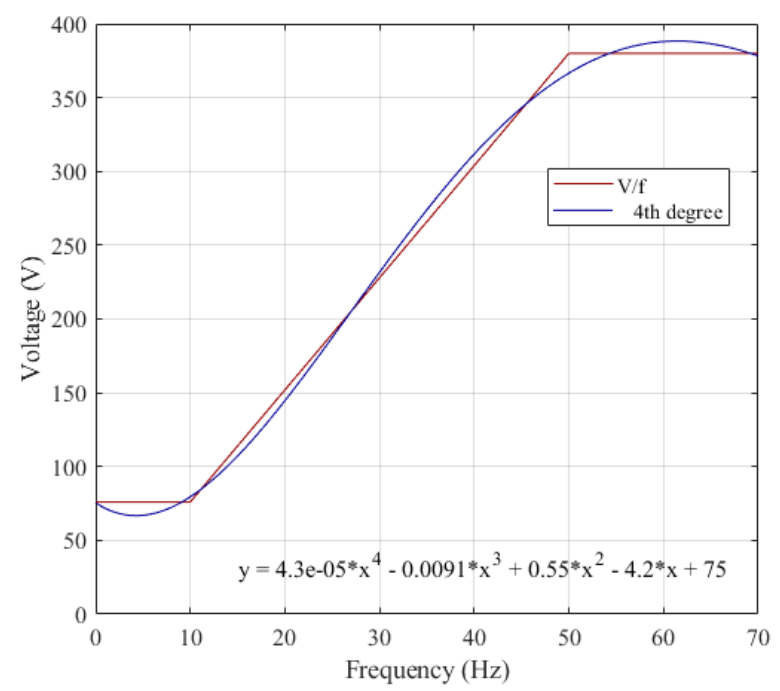

Figure 8. Polynomial fitted V/f curve

The three phase voltages are then,

$$
\begin{aligned}
& V_{a}=V_{s}^{*} \sin \left(2 \pi f_{s}^{*} t\right) \\
& V_{b}=V_{s}^{*} \sin \left(2 \pi f_{s}^{*} t+2 \pi / 3\right)
\end{aligned}
$$

and

$$
V_{c}=V_{s}^{*} \sin \left(2 \pi f_{s}^{*} t-2 \pi / 3\right)
$$

Figure 9 shows the generation of switching signals from the reference voltages obtained from the $\mathrm{V} / \mathrm{f}$ block using constant $\mathrm{V} / \mathrm{f}$ ratio.

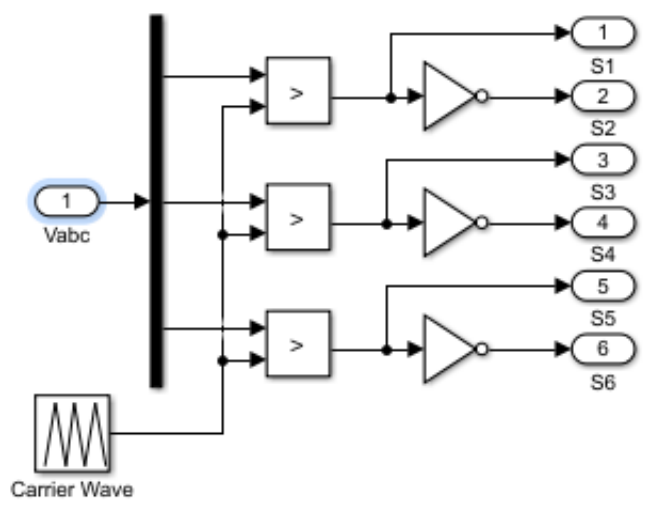

Figure 9. Simulink block for the switching signal generation

\section{EXPERIMENTAL SYSTEM AND RESULTS}

The experimental system consists of a voltage source inverter, a DSP with pc for control algorithm and a $0.5 \mathrm{~kW}, 1500 \mathrm{rpm}, 50 \mathrm{~Hz}, 3$-phase induction motor. Figure 10 shows the picture of the experimental rig. 


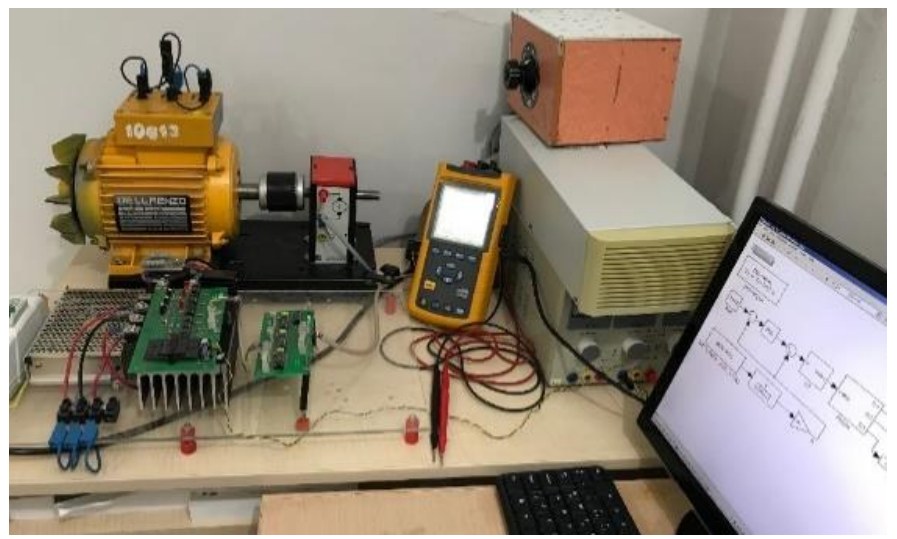

Figure 10. Experimental rig

The control system is developed in Matlab/Simulink environment with DS1103 dSPACE DSP. The DSP controller board uses a Real Time Interface and ControlDesk software for the implementation and experimentation respectively.

RTI toolbox provides Simulink blocks to configure models and to reach the DSP. ControlDesk provides a platform for controlling and monitoring the real-time control of the developed system. A control window with lots of virtual instruments can be build using ControlDesk. Thus real time parameter change and data acquisition can be made.

ControlDesk is used to monitor the operation, change the parameters online and capture the data. The speed obtained from the experimental system is filtered to avoid aliasing using an anti-aliasing filter.

The general block diagram of the speed control system is given in Figure 11.

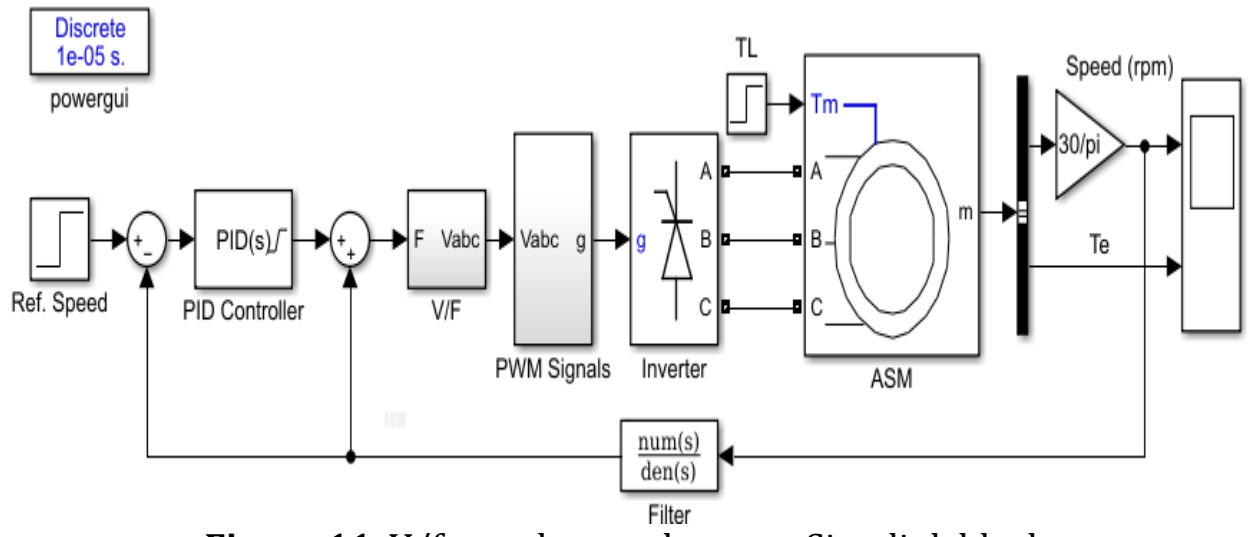

Figure 11.V/f speed control system Simulink block

A PI type controller with $\mathrm{K}_{\mathrm{P}}=0.01$ and $\mathrm{K}_{\mathrm{I}}=0.1$ is used to control the speed of the motor. Within the $\mathrm{V} / \mathrm{f}$ block, the magnitude and frequency of sinusoidal signals with $120^{\circ}$ phase shift are generated while keeping constant $\mathrm{V} / \mathrm{f}$ ratio based on a reference speed value. Sinusoidal reference signals are compared with a carrier triangular wave to produce PWM switching signals 
for the inverter switches. Since the change in the speed changes voltage and frequency to keep V/f constant which further changes the duty ratio of the switching signals, the inverter output voltage varies accordingly.

The Matlab/Simulink blocks for the DSP is given in Figure 12. Digital I/O ports are used for the inverter switching signal. Analog input port is used to receive the speed feedback signal for closed loop operation. This signal is used after filtered by a low pass filter to remove highf requency noise from encoder and amplified to the actual value.

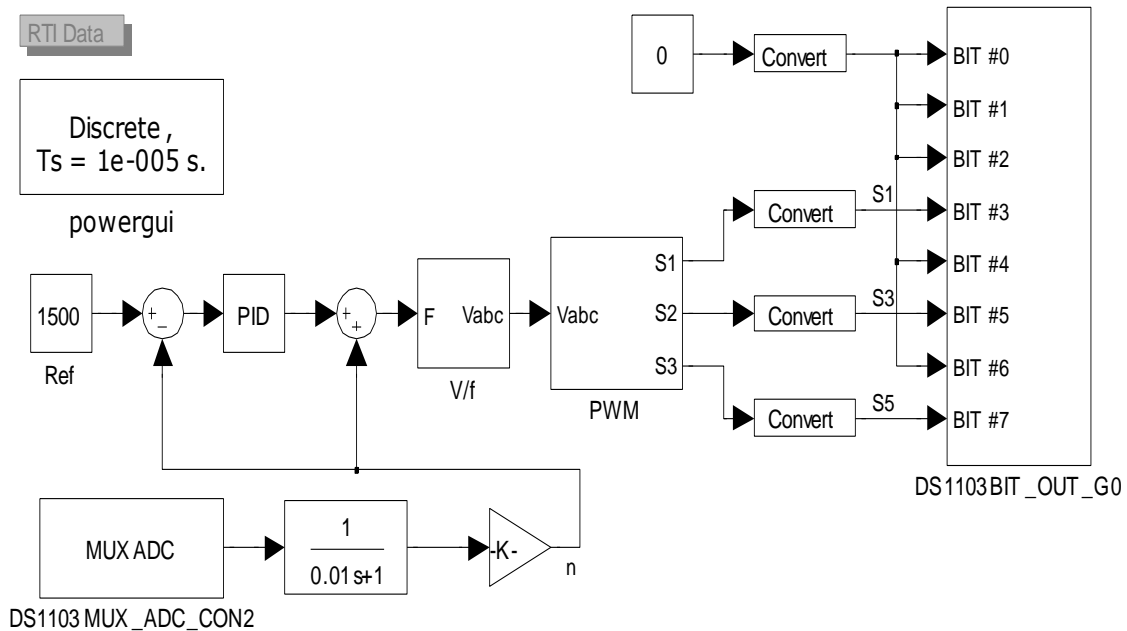

Figure 12. Simulink program for DSP

The speed response is obtained and presented using dSPACE ControlDesk software. Figure 13 shows the starting performance of the speed control system. The speed reference is given as $1500 \mathrm{rpm}$ and motor starts from rest.

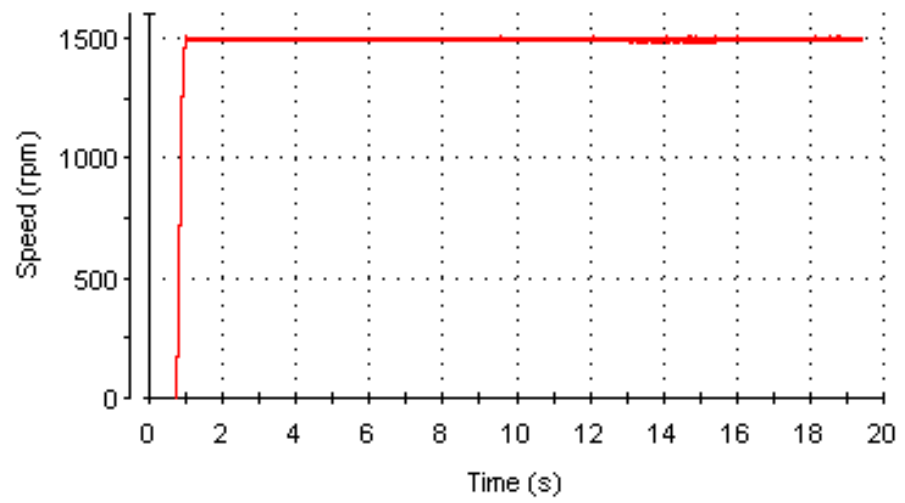

Figure 13. Speed response with $1500 \mathrm{rpm}$ reference speed

The reference speed is increased from 500 to $1000 \mathrm{rpm}$ and from 1000 to $1500 \mathrm{rpm}$. Then the reference speed is decreased from 1500 to $1000 \mathrm{rpm}$ and from 1000 to $500 \mathrm{rpm}$. The performance of the $\mathrm{V} / \mathrm{f}$ control system both increase in speed and decrease in speed is presented in Figure 14. 


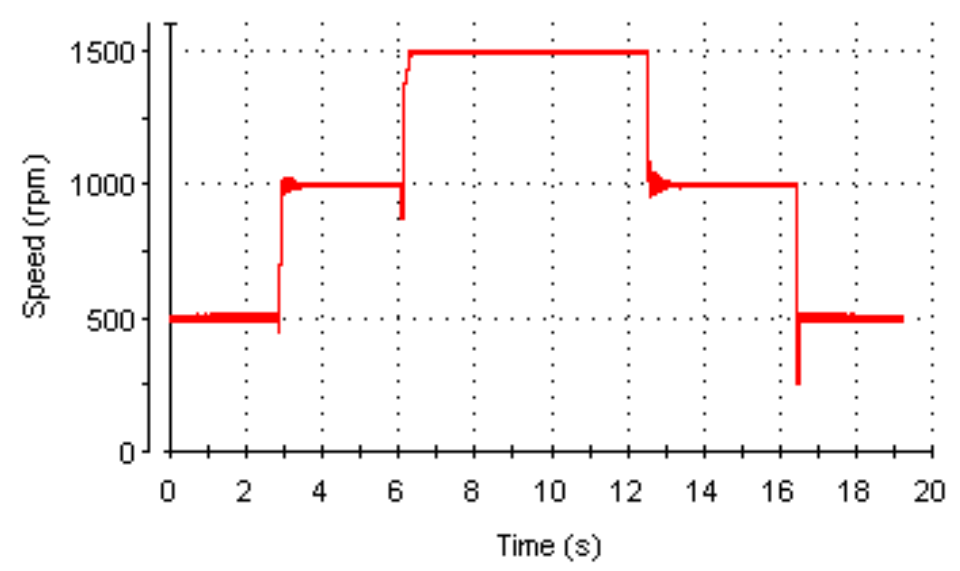

Figure 14. Speed response when both increase and decrease in reference speed

Figure 15 and Figure 16 represent the torque and speed recovery of the system when $3 \mathrm{Nm}$ load applied at $\mathrm{t}=2.5 \mathrm{~s}$ while motor running with no load.

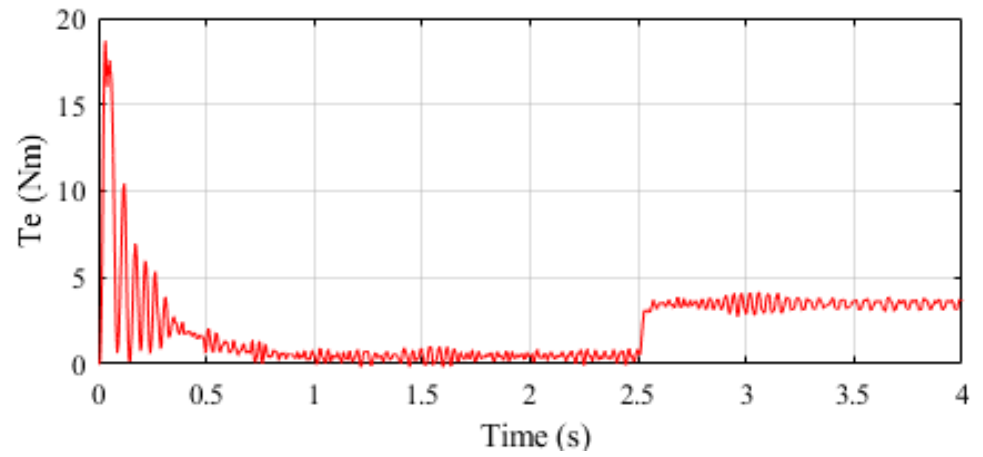

Figure 15. Torque response when $3 \mathrm{Nm}$ load is applied at $\mathrm{t}=2.5 \mathrm{~s}$

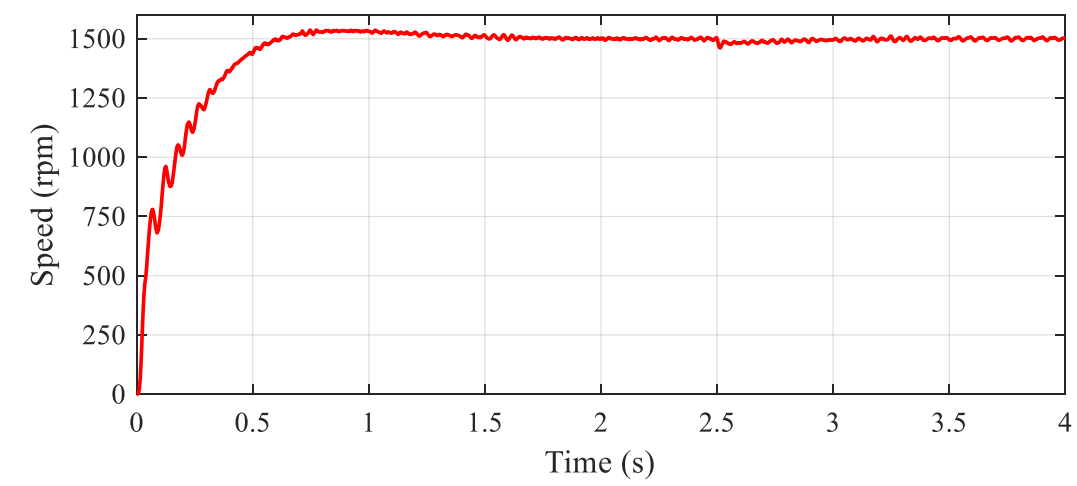

Figure 16. Speed response when $3 \mathrm{Nm}$ load is applied at $\mathrm{t}=2.5 \mathrm{~s}$

The system is tested with speed reversal. While the motor is stabilized running at $1500 \mathrm{rpm}$, a $1500 \mathrm{rpm}$ speed reference is applied. The performance with speed reversal is presented in Figure 17. Which shows the four quadrant operation of the controlled system. 


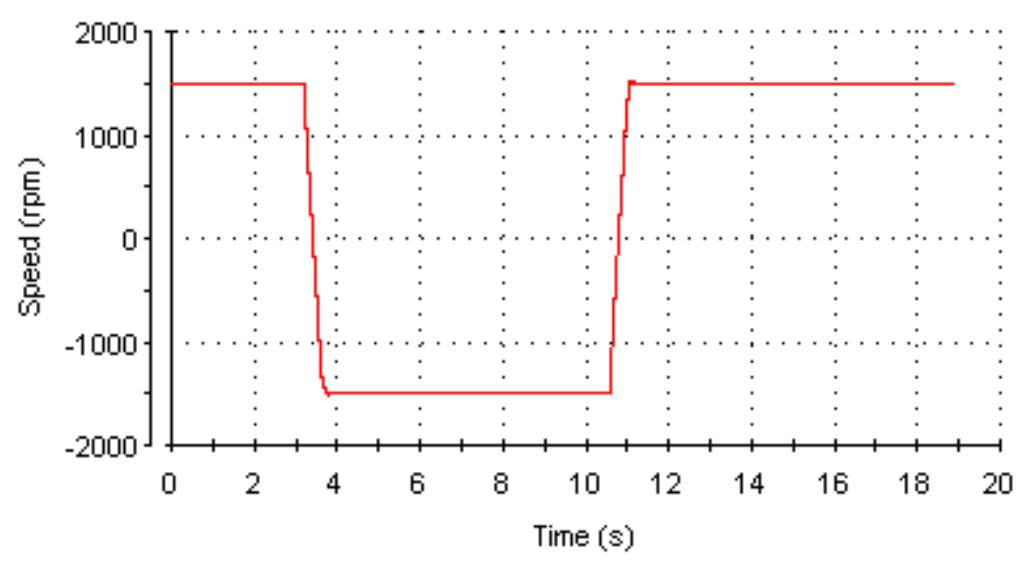

Figure 17. Performance at speed reversal

\section{CONCLUSION}

This study presents the speed control of a three phase induction machine using constant $\mathrm{V} / \mathrm{f}$ technique. The desired speed command is converted into the corresponding frequency. Reference voltages are generated from this desired frequency by keeping V/f to be constant. These reference voltages are compared with triangular wave producing switching signals.

The speed control system tested with different reference speed values including speed reversal. A good performance results are obtained and presented. The robustness of the system is tested with step load as well. The simulation results showed a good dynamic performance. This scalar control technique is simple to implement and low cost technique that can be used in many applications in industry.

\section{REFERENCES}

[1] Bimal Bose, Power Electronics and Motor Drives, Massachusetts, Academic Press, Elsevier, Ed. 1, 2006.

[2] Aung Zaw Latt, Ni Ni Win, Variable Speed Drive of Single Phase Induction Motor Using Frequency Control Method, IEEE International Conf. on Education Technology and Computer, Singapore, pp. 30-34, 2009.

[3] Ned Mohan, Tore Undeland, William Robbins, Power Electronics: Converters, Applications and Design, New York, John Wiley \& Sons, Ed. 2, 1995.

[4] Andrzej Trzynadlowski, Control of Induction Motors, San Diego, Academic Press, Ed. 1, 2001.

[5] Trupti Deoram Tembhekar, Improvement and Analysis of Speed Control of Three Phase Induction Motor Drive Including Two Methods, International Conf. on Emerging Trends in Engineering and Technology, Nagpur, India, pp. 736-741, 2009. 
[6] Jose Andres Santisteban, Richard Stephan, Vector Control Methods for Induction Machines: an Overview, IEEE Trans. on Education, Vol. 44, No. 2, pp. 170-175, 2001.

[7] Paul Krause, Oleg Wasynczuk, Scott Sudhoff, Steven Pekarek, Analysis of Electric Machinery and Drive Systems, New York, Wiley Interscience, Ed. 3, 2013.

[8] A. Abbondanti, Method of Flux Control in Induction Motors Driven by Variable Frequency, Variable Voltage Supplies, IEEE-IAS Int. Semi-Annual Power Conversion Conference, pp. 77-84, 1977.

[9] Alfredo Munoz-Garcia, Thomas Lipo, Donald Novotny, A New Induction Motor V/f Control Method Capable of High-Performance Regulation at Low Speeds, IEEE Trans. on Industry Applications, Vol. 34, No. 4, pp. 813-821, 1998.

[10] F. Blaschke, The Principle of Field-Orientation as Applied to the Transvector Closed-Loop Control System for Rotating-Field Machines, Siemens Rev., Vol. 34, No. 3, pp. 217-220, 1972.

[11] Isao Takahashi, Toshihiko Noguchi, A New Quick Response and High Efficiency Control Strategy of an Induction Motor, IEEE Trans. on Industry Applications, Vol. 22, No. 5, pp. 820-827, 1986.

[12] Shady M. Gadoue, Damian Giaouris, John W. Finch, Mras Sensorless Vector Control of an Induction Motor Using New Sliding-Mode and Fuzzy-Logic Adaptation Mechanisms, IEEE Trans. Energy Conversion, Vol. 25, No. 2, pp. 394-402, 2010.

[13] B.N. Singh, Bhim Singh, B.P. Singh, A comprehensive analysis of vector controlled induction motor drive, IETE Technical Review., Vol. 12, No. 5-6, pp. 387-398, 1995.

[14] A.E. Fitzgerald, Charles Kingsley, Stephan D. Umans, Electric Machinery, New York, McGraw-Hill, Ed. 6, 2003.

[15] Indra Ferdiansyah, Era Purwanto, Novie Ayub Windarko, Fuzzy gain scheduling of PID (FGS-PID) for speed control three phase induction motor based on indirect field oriented control (IFOC), EMITTER International Journal of Engineering Technology, Vol. 4, No. 1, pp. 237-258, 2016.

[16] Rizana Fauzi, R., Dedid Cahya Happyanto, Indra Adji Sulistijono, Fast Response Three Phase Induction Motor Using Indirect Field Oriented Control (IFOC) Based On Fuzzy-Backstepping, EMITTER International Journal of Engineering Technology, Vol. 3, No. 1, pp. 92$114,2015$.

[17] Stephan J. Chapman, Electric Machinery Fundamentals, Tata, McGraw-Hill, Ed. 4, 2010.

[18] Alexander L. Julian, Richard S. Wallace, Pradeep K. Sood, Multi-Speed Control of Single-Phase Induction Motors for Blower Applications, IEEE Trans. on Power Electronics, Vol. 10, No. 1, pp. 72-77, 1995. 